\section{International Scientific Journal Theoretical \& Applied Science}

\author{
p-ISSN: 2308-4944 (print) e-ISSN: 2409-0085 (online) \\ Year: 2015 Issue: 04 Volume: 24
}

Published: $30.04 .2015 \quad$ http://T-Science.org
Maxim Ruslanovich Moskalenko Associate Professor, Ph.D. Ural Federal University named after the first President of Russia Boris Yeltsin, Russia max.rus.76@mail.ru

SECTION 17. World History. History of Science and Technology.

\title{
SOME PROBLEMS OF TEACHING THE HISTORY OF SCIENCE AND TECHNOLOGY FOR STUDENTS ENGINEERING AND TECHNICAL SPECIALTIES IN RUSSIA
}

\begin{abstract}
This paper discusses the features of the teaching of history of science and technology for students engineering and technical specialties in Russia. Considered relevant and interesting questions for students: the main prevailing myths and misconceptions about various aspects the historical, scientific and technological development; specificity of scientific and technological forecasting; characteristics and patterns of development of scientific culture as an important factor of modernization. Studying these and other issues could expand the level of erudition and scientific horizon of future engineers and improve the quality of their training.

Key words: history of science and technology, engineering education.

Language: Russian

Citation: Moskalenko MR (2015) SOME PROBLEMS OF TEACHING THE HISTORY OF SCIENCE AND TECHNOLOGY FOR STUDENTS ENGINEERING AND TECHNICAL SPECIALTIES IN RUSSIA. ISJ Theoretical \& Applied Science 04 (24): 242-246.

Soi: http://s-o-i.org/1.1/TAS*04(24)44 Doi: crossef http://dx.doi.org/10.15863/TAS.2015.04.24.44

\section{НЕКОТОРЫЕ ВОПРОСЫ ПРЕПОДАВАНИЯ ИСТОРИИ НАУКИ И ТЕХНИКИ УЧАЩИМСЯ ИНЖЕНЕРНО-ТЕХНИЧЕСКИХ СПЕЦИАЛЬНОСТЕЙ В РОССИИ}

Аннотация: В данной работе рассматриваются особенности преподавания истории науки и техники учашиимся инженерно-технических специальностей в России. Выявляются актуальные и интересные для студентов вопросы: основные бытуюшие мифы и заблуждения относительно тех или иных аспектов исторического и научно-технического развития; специфика научно-технического прогнозирования; особенности и закономерности развития научных культур как важный фактор модернизаџии. Изучение этих и ряда других вопросов способно расширить уровень эрудиции и научный кругозор будущих инженеров и улучшить качество их подготовки.
\end{abstract}

Ключевые слова: история науки и техники, инженерное образование

\section{Введение.}

Современная высокотехнологичная экономика предполагает достаточно высокие требования к профессиональной квалификации работников инженерно-технического профиля. Необходимость модернизации инженерного образования, без которой России угрожает потеря конкурентоспособности и деиндустриализация, делает актуальным изучение исторического опыта научных достижений, технических открытий, научно-технологических прорывов и революций. В данном контексте большое значение приобретают вспомогательные дисциплины гуманитарного плана, и в особенности это касается курса «История науки и техники», читаемого в ряде вузов Российской Федерации.

Данный курс предполагает достаточно широкий круг изучаемого материала: ознакомление учащихся с творчеством крупных ученых и изобретателей; изучение фактов и закономерностей развития научного знания и техники в различные эпохи; рассмотрение особенностей научных революций, смены научных парадигм, а также анализ различных концепций научно-технической революции (НТР) и научно-технического прогресса (НТП) как важнейших вех развития человечества, целостное 
и системное осмысление которых закладывает культуру научного мышления будущего инженера. Отметим, что в ведущих западных вузах преподаванию истории науки и техники отводится очень большое значение [2].

\section{Основные вопросы курса.}

Многоплановость задач, решаемых данным курсом для подготовки инженерно-технических работников (ИТР), и ограниченность времени, отводимого для его освоения, заставляет сосредоточить внимание, прежде всего, на самых актуальных и интересных для учащихся аспектах истории научно-технического развития.

Прежде всего, в обществе в целом и в среде учащихся в частности достаточно широко распространены определенные заблуждения, мифы и не соответствующие реальности стереотипы относительно тех или иных аспектов исторического и научно-технического развития.

Первая группа мифов уходит своими корнями еще к дискуссиям западников и славянофилов XIX в., «Философическим письмам» П.Я. Чаадаева, и связана с представлениями об отсталости страны, которые, ввиду особенностей российского менталитета, часто переходят в убеждения об исторической ущербности российской цивилизации и «неполноценности» отечественной культуры [3]. Россия сравнивается, прежде всего, с развитыми странами Запада, и здесь очевидны, во-первых, серьезные отличия российской культурноисторической и политико-правовой традиции от западной (которая часто преподносится как эталонная), а, во-вторых, отставание в ряде областей научно-технического развития. Любой профессиональный историк отметит, что это совершенно нормальная ситуация для стран «догоняющей модернизации», или «второго эшелона» [1], в которых главная цель научнотехнического развития была подчинена оборонным задачам - не отстать от Запада в военном плане, чтоб не стать объектом колониальной экспансии. С этой задачей страна в целом справлялась, естественно, в ущерб развитию гражданского сектора экономики и общему уровню жизни населения. Но часто в массовом сознании негативные стороны отечественной истории абсолютизируются и воспринимаются вне исторического контекста.

Так, например, при изучении «соревнования» двух систем (СССР и США) студенты обращают внимание на отставание Советского Союза по ряду ключевых социальноэкономических показателей (особенно в уровне жизни населения). Но при этом часто совершенно не берут в расчет исходные, стартовые позиции двух стран в целом и степень ущерба от мировых войн в особенности. Например, результаты I
Мировой войны: для России - потеря миллионов убитыми, жесточайший системный кризис, гражданская война и разруха (на 1921 г. промышленное производство по сравнению с 1913 г. сократилось в 7 раз!), и для США практически никакого урона, огромная прибыль на военных заказах, новые производственные площади, положение мирового финансового центра. Почти столь же удручающими выглядят и сопоставительные результаты II Мировой войны. И вот на анализе подобных примеров у студентов формируются навыки сравнительноисторического подхода, которые совершенно необходимы для образованного человека.

Вторая групп мифов связана с неверными представлениями об отдельных аспектах истории техники, которые возникают в основном благодаря не совсем верным описаниям, представленных в литературных произведениях и кинематографе. Так, например, в советских фильмах о Великой Отечественной немецкие солдаты изображались в основном с пистолетомпулеметом МП-40 (ставший легендарным «Шмайсер», хотя конструктор Хуго Шмайсер имеет очень отдаленное отношение к конструированию данной модели). У зрителя складывалось впечатление об их серьезном преимуществе перед советской пехотой, вооруженной в основном винтовками Мосина, и это давало очередную пищу для упомянутого выше мифа об отсталости и ущербности России. Между тем, в начале войны подавляющее большинство немецкой пехоты было вооружено винтовками «Маузер 98» и карабинами «Маузер 98 к», которые лишь незначительно отличались от советской «трехлинейки» [5]. Конечно, художественная литература и кинематограф предполагает определенную долю вымысла и фантазии автора, но иногда они создают весьма обманчивое представление о действительности.

Третья группа мифов связана с неверными представлениями об особенностях отдельных периодов истории человечества. Так, например, когда заходит речь о первобытном обществе, то процветает заблуждение, что древнейшей профессией женщины была проституция («женщины древнейшей профессии» - такое выражение часто можно встретить в СМИ и популярной литературе.). Данный миф, вопервых, принижает место и роль женщины в мировой истории и культуре, создает ее исторически деструктивный образ, а, во-вторых, является серьезным искажением исторической действительности. Обычно объясняешь учащимся, что древнейшими занятиями женщин было воспитание детей, ведение домашнего хозяйства, собирательство и другие, связанные с хозяйственной деятельностью племени. 
Четвертая группа мифов и заблуждений связана с резким падением научной культуры общества в России по сравнению с советским периодом. Современные СМИ переполнены антинаучной, псевдотехнологической информацией - публикациями астрологических прогнозов, всевозможными рассказами о колдунах, экстрасенсах, пророчествах и т.д. Наглядный пример - недавняя массовая истерия в СМИ по поводу якобы ожидаемого в 2012 г. «конца света», который якобы должен наступить согласно таинственному «календарю индейцев майя» [6]. Чрезвычайно показательны данные опроса, проведенного ВЦИОМ в 2011 г.: каждый третий россиянин считает, что Солнце вращается вокруг Земли, а не наоборот, причем за последние годы таких «знатоков» стало на несколько процентов больше. Любопытны также другие заблуждения: радиоактивность - дело рук человеческих (55\%); люди жили в эпоху динозавров (29\%), а каждый пятый из опрошенных уверен, что полный оборот вокруг Солнца наша планета совершает за один месяц, пол ребенка определяют только материнские гены и т.п. [9]. И это происходит в обществе, которое (по статистическим данным) является одним из самых образованных в мире: в настоящее время высшее образование имеют 54\% россиян, причем по данному показателю Российская Федерация уступает всего трем странам - Южной Корее, Японии и Канаде [4].

Падение научной культуры связано с кризисом сциентизма (веры во всесилие науки, на которой была основана вся индустриальная цивилизация) и мировых идеологий (которые задавали ясный идеал будущего, структурировали реальность и отвечали на вопросы о смысле бытия человека и нации). Вера во всесилие прогресса и его способность решить все проблемы развития, которая была основной идеологической доминантой индустриальной цивилизации, уходит в прошлое [8]. Все это способствует возрождению веры в мистику и сверхъестественное, к критике возможности рационально-научного объяснения реальности. На этом фоне неудивительно, что достаточно широкое распространение получают паранаучные исторические концепции: о высокоразвитых цивилизациях древних русов, ариев, гиперборейцев; «новая хронология» А.Т. Фоменко и Г.В. Носовского; также популяризируются откровенные небылицы например, о создании гитлеровской Германией секретных подводных баз в Антарктиде в конце II Мировой войны и др. Это создает достаточно мозаичную и синкретичную картину мира в современных СМИ, где научно доказанные факты и концепции пересекается с мифами и далекими от науки измышлениями, и все это отрицательно сказывается на научной культуре общества в целом и студенчества в частности.

Кроме данных мифов и заблуждений, актуальным и интересным для студентов аспектом курса является специфика научнотехнического прогнозирования. Научно обоснованный анализ тенденций развития и различных футурологических построений всегда представлял большой интерес для обучающихся и специалистов. Кроме того, в условиях скачкообразного ускорения научно-технического развития большую важность для будущих профессионалов приобретают навыки прогнозирования в профессиональной деятельности. Еще в 1970-е гг. известный американский футуролог А. Тоффлер в своем бестселлере «Футурошок» отмечал, что система образования должна готовить специалистов, которые могут принимать критические решения, находить свой путь в новом окружении, которые достаточно быстро устанавливают новые отношения в быстро меняющейся реальности. Она требует людей, у которых «будущее в крови». Обязанностью образования должно стать повышение «способности индивидуума справляться» - той скорости и экономии, с которой он может приспособиться к реальным изменениям Человек должен научиться предвидеть направление и уровень изменений. Он должен, говоря техническим языком, научиться делать повторяющиеся вероятностные, по возрастающей, долговременные заключения о будущем. И то же самое должны делать учителя этого человека [10].

Естественно, что инженерам в своей будущей профессии придется иметь дело с анализом научно-технических прогнозов, и они должны знать их специфику. Если кратко охарактеризовать их особенности, то они таковы:

1. Значительный временной разрыв между фундаментальным открытием в науке и его прикладным применением. Например, фундаментальные исследования свойств атома и радиоактивного излучения начались в 1890-е гг., a на практике это нашло применение только несколько десятилетий спустя: 1945 - военное использование атома, 1954 - первая АЭС.

2. Неочевидность прикладного и коммерческого эффекта от крупных фундаментальных открытий и изобретений. Например, одно из крупнейших фундаментальных открытий в физике XX в. создание А. Эйнштейном теории относительности - до сих пор имеет достаточно узкую сферу применения, преимущественно в астрономии. Ее появление не привело к прорывам в технологии.

Эти особенности объясняют, почему на современном этапе не только коммерческие, но и 
государственные структуры часто не желают тратить средства на фундаментальные научные разработки: слишком неочевидна их практическая направленность и прикладной эффект. А ученым даже в развитых странах, чтобы обеспечить финансирование фундаментальных разработок, приходится порой идти на подлог результатов опытов и экспериментов, чтобы сделать рекламу своим научным разработкам и под новое «сенсационное открытие» (которое часто представляет собой не научно доказанную теорию, а всего лишь гипотезу-предположение) попросить средства на продолжение исследований.

3. Нелинейный характер развития техники и технологии. Это отчетливо видно на примере ряда изобретений. Например, космическое ракетостроение в период примерно с 1950-х по 1970-е гг. развивалось скачкообразно поколения ракет менялись каждые несколько лет, каждая последующая модель намного превосходила предыдущую по грузоподъемности, дальности и точности полета и другим техническим характеристикам. А начиная с 1970-х гг. - более медленное, плавное развитие данной отрасли. Или, например, в развитии судостроения XIX-XX вв. также можно отметить своеобразные циклы - периоды скачкообразного увеличения тоннажа, скорости, мощности машин, прочности кораблей сочетались с периодами замедления темпов роста этих характеристик. Данные скачки и циклы технологического прогнозирования очень важны для грамотного формирования целей и задач развития соответствующих отраслей экономики и понимания закономерностей технического развития общества.

В истории науки и техники одной из ключевых проблем являются также особенности и закономерности развития научных культур как важный фактор модернизации.

Bo-nервыl, существует комплекс вопросов, связанный с проблемой расцвета и упадка научных культур. Например, с чем связаны расцвет немецкой науки во 2-й пол. XIX - 1-й пол. ХХ в. и ее упадок после 1945 г.? Или расцвет советской науки в 1950-60-е гг. и затем ее постепенный упадок? Только ли с тотальными военными и политическими поражениями этих стран (Германия потерпела такое поражение в 1945 г., СССР - в 1991 г. в «холодной войне»)? Но ведь торможение прогресса науки началось в этих странах задолго до поражений. Еще до начала II Мировой войны, из Германии времен Гитлера выехало несколько десятков знаменитых ученых. Научные работники и исследователи в III Рейхе отмечали, что «расовый миф» крайне негативно влияет на научную культуру: воспитанники спецшкол СС сомневались в научных открытиях, совершенных «неарийцами». Или, например, концепция «расовой чистоты» противоречила доказанному биологами утверждению, что дети от смешанных межнациональных браков генетически более здоровы. Можно привести и другие примеры, которые подтверждают, что, даже если бы III Рейх существовал и дальше, после 1945 г., то развитие науки в нем, скорее всего, замедлилось бы. Что касается советской науки, то ее упадок и падение эффективности начались еще задолго до политического кризиса в СССР. На примере этих двух стран видна одна из основных прикладных проблем истории науки и техники: как возникает и развивается научная культура? Какие факторы способствуют ее расцвету или упадку? Всесторонний, концептуальный анализ данных проблем может способствовать выработке стратегии реформирования науки в любой стране [7].

Bo-вторых, большой интерес представляет изучение историко-культурных механизмов способности общества к восприятию и внедрению ноу-хау, а также зарождению и эволюции социальных институтов, способствующих либо препятствующих развитию инноваций и технологий. Так, в средневековом Китае ряд интересных изобретений появилось намного раньше, чем в Европе (книгопечатание, медицинские прививки и др.), но затем произошло серьезное отставание в развитии. В позднем СССР также промышленность (за исключением ВПК) не могла освоить большинство интереснейших изобретений, которые давали инженерыизобретатели. Комплексный анализ данных механизмов необходим для более эффективной стратегии модернизации.

$B$-третьих, не теряют свою остроту вопросы адаптации незападных обществ к НТР и НТП, тесно связанные с комплексной проблемой «догоняющей модернизации». Формирование благоприятной для модернизационных процессов научной и образовательной среды с учетом национальных особенностей и специфики менталитета является одной из ключевых задач политики модернизации (здесь наиболее показателен пример Японии).

\section{Заключение.}

Подводя итоги работы, отметим наиболее интересные и актуальные вопросы в преподавании истории науки и техники для учащихся инженерно-технических специальностей: анализ основных мифов и заблуждений относительно тех или иных аспектов исторического и научно-технического развития; специфика научно-технического прогнозирования; особенности и закономерности 
развития научных культур как важный фактор модернизации. Изучение этих и ряда других вопросов способно расширить уровень эрудиции и научный кругозор будущих инженеров и улучшить качество их подготовки.

\section{References:}

1. (2015) Eshelony modernizatsii i problema «dogonyaushego» razvitiya. Available: http://vse-uchebniki.com/uchebnikistoriya/eshelonyi-modernizatsii-problemadogonyayuscheg.html (Accessed: 25.04.2015).

2. (2015) History of science and technology. Available:

http://en.academic.ru/dic.nsf/enwiki/8564 (Accessed: 25.04.2015).

3. (2015) Geopoliticheskiye myphy o Rossii. Available:

http://studme.org/1147021228204/politologiya/ geopoliticheskie_mify_rossii (Accessed: 25.04.2015)

4. (2014) Innovacionnaya obrazovatelnaya set «Evrika».

Available: http://eurekanet.ru/ewww/promo_print/18679.ht ml (Accessed: 26.01.2014)

5. Isaev AV (2004) Antisuvorov. Desyat mifov Vtoroy mirovoy. Moscow: Eksmo, Jauza, 2004.

6. (2015) Konec sveta v 2012 po kalendarju mayia-shutka uchenikh. Available: http://2012over.ru/konec-sveta-v-2012-pokalendarju-majija-shutka-uchenikh.html (Accessed: 25.04.2015)

7. Moskalenko MR, Doroshenko VA (2012) Uchebnaya disciplina «Istoria nauki I techniki» v kontexte evolutsii sistemy obrazovaniya // Izvestiya Uralskogo Federalnogo universiteta. Seria 1. Problemy obrazovaniya, nauki i kultury. 2012. № 3 (104). pp. 33-40.

8. Shanin T (1996) The Idea of Progress // The Post-Development Reader / Ed. M.Rahneman, V.Bawtree. L., 1996.

9. (2014) «Solnce-sputnik Zemli», ile rating nauchnyh zabluzhdeniy rossiyan // Oko planety. Press-vipusk № 1684. Available: http://okoplanet.su/science/sciencediscussions/59853solnce-naznachili-sputnikom-zemli.html (Accessed: 26.01.2014).

10. Toffler A (1970) Future shock. New York: Random House, 1970. 